\section{Abordagem profissional da violência familiar contra o idoso em uma unidade básica de saúde}

\author{
A professional approach to family violence against \\ the elderly in a primary health clinic
}

\section{Enfoque profesional de la violencia familiar contra personas mayores en una unidad basica de salud}

\author{
1 Universiade Tuiuti do \\ Paraná, Curitiba, Brasil. \\ 2 Universidade Federal \\ de Santa Catarina, \\ Florianópolis, Brasil. \\ Correspondência \\ A. C. N. S. Wanderbroocke \\ Universidade Tuiuti do \\ Paraná. \\ Rua Sydnei Rangel Santos \\ 238, Curitiba, $P R$ \\ 82010-330, Brasil. \\ anawdb@gmail.com
}

\begin{abstract}
This article aims to describe a professional approach in a primary health clinic towards family violence against the elderly. This qualitative study collected data through participant observation recorded in a field diary, in addition to semi-structured interviews. Ten health workers from the clinic participated in the interviews. Data were analyzed according to Grounded Theory, and two categories were discussed: professional approach to domestic violence against the elderly and the clinic's management of situations involving such violence. The data point to professionals' difficulties in identifying violent situations and beliefs related to the inability to cope with it. In institutional terms, the data also highlight factors that hinder detection of cases, such as limited emphasis on interdisciplinary work and routines focused on physical health. The study suggests the need to offer health workers the opportunity to reflect on domestic violence and possibilities for intervention.
\end{abstract}

Aged; Domestic Violence; Health Personnel; Primary Health Care
Ana Claudia Nunes de Souza Wanderbroocke 1 Carmen Leontina Ojeda Ocampo Moré 2

\section{Resumo}

O presente artigo tem como objetivo descrever a abordagem profissional da violência familiar contra idosos em uma unidade básica de saúde (UBS). Trata-se de pesquisa qualitativa, com dados coletados por meio de observação participante com registro em diário de campo e entrevistas semiestruturadas. Participaram das entrevistas dez profissionais da UBS. Os dados foram analisados segundo o referencial da Grounded Theory e duas categorias foram discutidas: manejo profissional de situações de violência familiar contra o idoso e condições da UBS para atender a situações de violência familiar contra o idoso. Os dados apontam para dificuldades dos profissionais de identificar situações de violência e crenças relacionadas à impossibilidade de enfrentá-la. Em termos institucionais, os dados indicam fatores que desfavorecem a detecção e acompanhamento dos casos como a menor ênfase no trabalho interdisciplinar e rotinas voltadas para a saúde física. O estudo sugere a necessidade de oferecer aos profissionais oportunidade para a reflexão sobre violência e possibilidades de intervenção.

Idoso; Violência Doméstica; Pessoal de Saúde; Atenção Primária à Saúde 


\section{Introdução}

Violência familiar acompanha toda a história da Humanidade, porém só a partir da segunda metade do século XX começou a merecer atenção dos profissionais da saúde 1 . Atualmente, os estudos sobre violência familiar têm buscado gradativamente compreender as situações de violência contra os idosos. Fato motivado tanto pelo aumento do contingente de idosos quanto pelas pesquisas nacionais e internacionais que apontam a família como o principal contexto de ocorrência de violências contra esse grupo etário 2,3,4.

Os serviços de atenção primária são estratégicos para lidar com casos de violência familiar, uma vez que funcionam como a porta de entrada dos serviços públicos de saúde. A literatura da última década sobre a abordagem da violência familiar por profissionais da atenção primária informa que os profissionais já vêm incorporando em suas rotinas as determinações de políticas públicas direcionadas ao enfrentamento da violência familiar, especialmente contra mulheres e crianças 5,6,7,8. Contudo, esse movimento não ocorre sem dificuldades.

A tarefa dos profissionais junto aos usuários é bastante complexa porque, além de acolher e detectar a violência, precisam acompanhar os casos. Porém, na maioria dos serviços de saúde se encontram organizações rigidamente hierarquizadas, com o predomínio da responsabilização do médico, a falta de diretrizes técnicas para a abordagem e encaminhamento dos casos e muitas vezes, pouca eficácia, observada pelos profissionais, quanto à resolução dos encaminhamentos efetivados.

Além das barreiras impostas pela formação e organização dos serviços, pode ocorrer de o profissional identificar a situação e a pessoa vitimada recusar o atendimento, ocultar o fato ou negar o ocorrido, impondo barreiras ainda mais difíceis de transpor 9,10 . Outros pesquisadores consideram que a dificuldade em todo o processo está na sua complexidade, já que não depende apenas da discussão da temática no cotidiano dos serviços de saúde, em capacitação profissional e interdisciplinaridade, senão do estabelecimento de parcerias com outros serviços, ou seja, da intersetorialidade $6,11,12,13,14$.

A falta de preparo para lidar com situações de violência familiar se relaciona ao sentimento de impotência, que surge quando o profissional se depara com a questão e não se sente suficientemente capacitado para abordá-la. Além desse sentimento, dados de pesquisas indicam o medo do profissional pela perda de controle da situação, de ser invasivo e ofensivo, de cometer injus- tiça com a pessoa atendida, caso a suspeita não se confirme. Soma-se ainda, o temor da exposição e de represálias por parte do agressor 5,6,7.

Os diferentes sentimentos gerados no manejo dos casos podem levar a dificuldade de estabelecer fronteiras entre o profissional e o pessoal 15 . As consequências podem ser o desenvolvimento de desordens psicossomáticas, sensação de desconfiança, desânimo, perda de sentido no trabalho, rebaixamento da autoestima, entre outros, que repercutem tanto na vida laboral quanto na pessoal e conjugal 8,16 .

Por outro lado, os profissionais de saúde podem transpor para a relação profissional crenças desenvolvidas nas vivências pessoais, achando que em alguns casos a violência pode ser considerada "normal", como também o receptor pode ser visto como merecedor ou culpado da violência sofrida 2 . Nesse contexto, o profissional faz uma leitura com base no próprio desenvolvimento e história de vida, favorecendo que situações de violência permaneçam na invisibilidade.

Apesar das dificuldades enfrentadas pelos profissionais da saúde, na última década o Brasil avançou na implementação de políticas públicas de combate à violência contra as pessoas idosas, a partir da promulgação do Estatuto do Idoso $17 \mathrm{e}$ do Plano de Enfrentamento da Violência Contra a Pessoa Idosa 18. Se por um lado caracterizam um avanço do país para buscar atender às necessidades desse grupo etário, por outro, gerou novas demandas aos profissionais que atuam na atenção primária, sem que as antigas tenham sido superadas.

Como a literatura sobre a abordagem de casos de violência contra idosos ainda é incipiente no Brasil, cabe investigar a práxis de profissionais que atuam no contexto da atenção primária. Com base no exposto, este estudo tem como objetivo descrever a abordagem profissional da violência familiar contra idosos em uma unidade básica de saúde (UBS).

Pretende-se, por este estudo, evidenciar as situações de violência familiar contra os idosos, cada vez mais comuns no cotidiano dos serviços de saúde, com o intuito de gerar bases para melhor qualificação dos profissionais na escuta dessa temática.

Os dados apresentados neste artigo são parte de uma pesquisa maior, realizada durante o ano de 2009 e já concluída, que buscou os significados da violência familiar contra idosos, no contexto da atenção primária à saúde, na perspectiva dos profissionais e dos usuários idosos. 


\section{Método}

\section{Participantes}

Fizeram parte do estudo 10 profissionais com diferentes formações: médico, enfermeiro, técnico em enfermagem, assistente social, agente comunitário e odontólogo. Os profissionais foram selecionados levando-se em conta três critérios: (a) diferentes formações profissionais; (b) atuação voltada aos usuários idosos; e (c) dois anos, no mínimo, de tempo de trabalho na unidade de saúde.

A amostra foi composta por 8 mulheres e 2 homens, com idade entre 24 e 68 anos, com pelo menos dois anos de trabalho na UBS.

\section{Local}

A pesquisa foi realizada em uma UBS referência na atenção integral à saúde da população idosa, localizada em uma capital da Região Sul do Brasil.

\section{Instrumentos}

Inicialmente, foi utilizada a observação participante com registro em diário de campo, concebida como um processo gradual de acesso ao campo, possibilitando contato direto com o fenômeno a ser pesquisado.

Entrevistas semiestruturadas foram realizadas com os profissionais, com base em um roteiro estruturado para o levantamento de dados sociodemográficos e perguntas norteadoras relacionadas ao objetivo do trabalho.

\section{Procedimentos}

A observação participante foi realizada no período de coleta de dados, combinando simultaneamente a observação direta, participação em atividades e conversas informais. Foi fundamental para alcançar os seguintes objetivos: auxiliar no levantamento de dados sobre a estrutura e funcionamento da UBS; perceber a rotina dos profissionais e idosos dentro da UBS; manter uma presença constante no campo; introduzir o diálogo sobre situações de violência com os diferentes atores sociais; verificar pensamentos, crenças e procedimentos dos profissionais frente a relatos de situações de violência familiar contra idosos; registrar elementos sutis, relacionados ao entendimento da dinâmica complexa, instável e intersubjetiva da questão em estudo em relação ao contexto pesquisado e identificar os participantes, melhores momentos e locais para as entrevistas.
Para as entrevistas foi feito contato individual com os participantes a fim de expor os objetivos e convidá-los a fazer parte do estudo. Os profissionais puderam optar pelo horário e local para a realização das entrevistas, considerando suas atividades. Não houve recusa para a participação na pesquisa.

Foi realizada uma entrevista com cada profissional e se definiu o número de participantes em função da saturação de dados 19 que começou a se delinear na sexta entrevista, quando foram observadas regularidades nas informações e reincidência temática. Dessa maneira, optou-se por realizar mais quatro, completando o total de 10 entrevistas a fim de confirmar a recorrência dos dados obtidos.

Todo o trabalho foi orientado a fim de atender às normas da Resolução no 196/96 do Conselho Nacional de Saúde, tendo o projeto sido aprovado pelo Comitê de Ética em Pesquisa da Universidade Federal de Santa Catarina (parecer no 240, emitido em 03/Nov/2008) e pela Secretaria Municipal de Saúde da cidade onde a pesquisa foi realizada.

\section{Análise dos dados}

Para a análise dos dados, foi utilizado o método Grounded Theory 19. Esse método de análise permite trabalhar, comparar, integrar e categorizar os dados obtidos. A primeira etapa, denominada codificação aberta, consiste em realizar sucessivas leituras das entrevistas, seguidas do processo de desmembramento, exame, comparações e categorização dos dados. Na segunda etapa, denominada codificação axial, realiza-se a construção das categorias principais, subcategorias e seus respectivos elementos de análise. Por último, o processo de codificação seletiva, permite integrar e refinar o conjunto de dados obtidos, proporcionando compreensão integrada do fenômeno central. O processo de refinamento se baseia no critério da saturação de dados, ou seja quando não aportam novas informações às já reconhecidas e organizadas.

Duas categorias foram selecionadas para responder ao objetivo do presente artigo: (a) manejo profissional de situações de violência familiar contra o idoso; e (b) condições da UBS para atender a situações de violência familiar contra o idoso.

Assim, as categorias apresentadas neste estudo foram construídas pelas autoras e desdobram-se em subcategorias e elementos de análise, abstraídas das narrativas dos profissionais e dos registros do diário de campo. Cabe ressaltar que a construção do processo de categorização se sustentou num processo recursivo constante 
até o momento em que não se observaram novas informações relacionadas, tanto aos objetivos específicos, como ao objetivo geral da investigação. Tal organização possibilita uma leitura transversal dos dados, como também uma análise em profundidade do conteúdo emergente nas entrevistas. As categorias, subcategorias e elementos de análise podem ser mais bem visualizadas na Tabela 1.

\section{Resultados e discussão}

A primeira categoria, "manejo profissional de situações de violência familiar contra o idoso", abordou a forma de conduzir as situações que envolvem indícios ou a confirmação de violência familiar contra o idoso. Na subcategoria "condutas que facilitam a identificação e a abordagem" apontou-se o que é feito ou considerado adequado para prevenir ou administrar casos suspeitos de violência familiar contra o idoso. Os participantes consideraram a avaliação global e sequencial como essencial para rastrear e lidar com casos de violência, o que implica abordar aspectos de diferentes áreas, como a avaliação da saúde física, psicológica e social durante o contato com o usuário e acompanhar os casos atendidos. Complementando esse aspecto da conduta, o oferecimento de escuta ao idoso e a disponibilidade ao idoso e aos familiares, para tirar dúvidas sobre o tratamento ou outras questões, mesmo em horário não agendado, também foi mencionado.

"Você conversando com a pessoa, olhando como ser humano você percebe que tem alguma coisa e você dando oportunidade, a pessoa vem e fala alguma coisa. Sempre acabam falando. (...) Você tem que conversar e mostrar que está interessada na vidinha dele, no bem estar dele. (...) Daí quando ele começa a contar ou chorar, tem que esperar um pouco pra ver até onde ele vai criar um vínculo de confiança com você pra te contar..." (P1).

As condutas citadas pelos profissionais constituem as peculiaridades fundamentais da atenção primária em saúde, conforme a proposta do Sistema Único de Saúde (SUS) de assistência longitudinal e continuada e oferecimento de ações de saúde que contemplem uma visão integral às pessoas atendidas. Portanto, os profissionais precisam usar a escuta como um instrumento de trabalho a fim de dar voz ao usuário, levantar as suas necessidades e buscar soluções para as demandas, o que consiste no acolhimento ao usuário 20 .

Categorias, subcategorias e elementos de análise.

\begin{tabular}{|c|c|c|}
\hline Categoria & Subcategoria & Elemento de análise \\
\hline Manejo profissional de situações de violência & Condutas que facilitam a identificação & Avaliação global e sequencial \\
\hline \multirow[t]{12}{*}{ familiar contra o idoso } & e a abordagem & Escuta ao idoso \\
\hline & & Disponibilidade ao idoso e aos familiares \\
\hline & & Investigação de sinais ou sintomas suspeitos \\
\hline & & Busca da rede de suporte do idoso \\
\hline & & Trabalho em equipe \\
\hline & Situações que dificultam a identificação & Definição de violência \\
\hline & e a abordagem & Desacreditar no que a pessoa idosa relata \\
\hline & & Idoso não considera ou não sinaliza que a \\
\hline & & situação o perturba \\
\hline & & Silêncio do idoso \\
\hline & & Revelação tardia \\
\hline & & Revelação e recusa de intervenção profissional \\
\hline \multirow{7}{*}{$\begin{array}{l}\text { Condições da unidade básica de saúde para } \\
\text { atender a situações de violência familiar } \\
\text { contra o idoso }\end{array}$} & Dinâmica de trabalho & Ausência de interdisciplinaridade \\
\hline & & Sobrecarga de trabalho \\
\hline & & Ênfase na saúde física \\
\hline & Preparo da equipe para lidar com situações & Falta de capacitação \\
\hline & de violência & Falta de conhecimento das políticas públicas \\
\hline & & Ineficácia das ações \\
\hline & & Falta de medidas de rastreamento \\
\hline
\end{tabular}


Vale ressaltar a importância de os profissionais da saúde reconhecerem que a escuta profissional é uma ferramenta que previne esse agravo e por seu intermédio se possibilita apoio e informação às vítimas 21 . O envolvimento e a prestação de serviço ao usuário foram verificados na atitude de vários profissionais que desempenhavam seu papel da melhor maneira possível, apesar de a dinâmica da UBS nem sempre propiciar esse comportamento.

Acompanhar os casos atendidos de forma global e sequencial permite ao profissional o estabelecimento de um espaço de confiança para a investigação de sinais ou sintomas suspeitos de violência. Essa conduta, juntamente às apresentadas nos elementos de análise anteriores, são as indicadas para os profissionais da saúde, como procedimentos de diagnóstico e abordagem terapêutica de situações envolvendo violência familiar contra o idoso 18. "É uma coisa pra se inves tigar melhor, tentar saber como é esse ambiente, se aconteceu outras vezes, se é de fato frequente, pra que você possa tentar ajudar" (P3).

Apenas um profissional se referiu à busca da rede de suporte do idoso, contatando mais de um familiar ou vizinho ao suspeitar de dificuldades nos cuidados oferecidos ao idoso. "Se tem mais filhos eu procuro a família para ver se podem dar apoio, estar mais junto, se pode levar a pessoa que é mais impotente para casa, já cansei de incomodar filhos, cunhados" (P5).

Os profissionais ressaltaram o trabalho em equipe como iniciativa possível no caso de suspeita de violência familiar. A importância do trabalho interdisciplinar para os entrevistados ratifica o argumento de que um saber apenas é insuficiente para a compreensão e abordagem do fenômeno da violência como um todo 21 . Entretanto, nas falas dos participantes, percebeu-se por um lado o envolvimento de alguns profissionais que discutiam e/ou buscavam ajuda de colegas ou outros setores para acompanhar conjuntamente o caso suspeito ou confirmado, a fim de se aproximar da complexidade das situações e de um modelo interdisciplinar de atuação. Por outro lado, alguns realizavam o encaminhamento desses casos para outros profissionais, considerados mais capacitados para resolver o impasse e se eximiam de dar sequência ao atendimento, privilegiando o modelo de atuação multiprofissional, vale dizer, cada profissional atuando dentro de sua especialidade, sem a busca de uma integração das ações e conhecimentos 4,22.

"Então você aguarde um minutinho, disse pra senhora [suspeita de sofrer violência] fui lá e chamei a enfermeira, na época tinha uma assistente social e uma psicóloga, falei 'vão lá e vejam o que vocês podem fazer'. Acionei, não sei se consegui- ram resolver toda a situação, pelo menos aqui ela sentiu que não estava só” (P5).

A subcategoria "situações que dificultam a identificação e a abordagem” enfocou o que ocorre na relação entre o usuário e o profissional, para evitar a manifestação ou o manejo das situações de violência. Os profissionais descreveram a dificuldade quanto à definição de violência, porque, mesmo cientes de que ela extrapola as agressões físicas, na prática, ainda é o que mais mobiliza o profissional, como a seguinte narrativa revela: “Eu assim, eu tanto que escuto que a gente vê se consegue ajudar. Eu não vi muitos casos sobre violência mesmo, a física" (P7).

Outro fator que dificulta a constatação de um caso de violência é desacreditar no que a pessoa idosa relata, ao se mostrar muito prolixa ou queixosa. "Assim como tem aqueles que falam demais, se queixam demais e a gente fica desconfiada se é tudo isso que eles dizem" (P1).

Por outro lado, pode ocorrer que o profissional suspeite, mas fique sem ação porque o idoso não considera ou não sinaliza que a situação o perturba.

"Pois é, o filho diz para mim que ele tem demência, mas eu não sei até que ponto isso é verdade porque eu converso com ele e ele entende, ele entende, eu explico o que eu vou fazer e ele me dá um retorno, então não sei até que ponto eu posso confiar na palavra dele. Ele é exaltado, ele é agressivo com o pai. (...) Eu às vezes me sinto muito incomodada com isso e gostaria de ajudar de alguma forma, mas é uma situação delicada, convenhamos que é uma situação delicada" (P10).

A narrativa acima denota a contradição com o apresentado na subcategoria precedente no que diz respeito a avaliar de forma global e sequencial, a investigar os sinais e sintomas suspeitos de violência, bem como a trabalhar em equipe. Condutas que favoreceriam o esclarecimento da situação e possibilitariam que os casos fossem eficientemente manejados.

Portanto, as entrevistas dos profissionais indicaram uma distância entre o saber teórico e a realidade prática cotidiana. A falta de capacitação que proporcione a reflexão sobre o que é violência 14 e os valores e crenças de cada pessoa sobre o tema favorece a manifestação somente de casos mais extremos 23 , geralmente, os que envolvem maus-tratos físicos ou denúncia 2,10.

Os relatos, como o exemplo acima sugere, apontaram para o descrito por pesquisadores da área, sobre o medo de ser invasivo, cometer injustiça com o idoso ou com o familiar e expor a vida alheia 5,6,7. Esse temor inibe o profissional na investigação dos casos suspeitos e a dúvida se presta como uma aliada para que o caso não seja investigado adequadamente, protegendo o 
profissional desses casos incertos. As informações confirmam o argumento de que a tolerância social dos casos de violência familiar se relacionam com a crença socialmente construída a respeito da privacidade familiar ou aos preconceitos pessoais, impedindo a ação profissional 2 .

Os profissionais mencionaram o silêncio do idoso, relacionado às violências sofridas, e indicaram a falta de atitude por medo de retaliação do agressor, sentimento de vergonha, incapacidade de o idoso se manifestar por se encontrar muito fragilizado, ou o fato de ele esconder suas dificuldades de autocuidado para que os familiares não sejam acionados e ele perca a sua autonomia, como o relato abaixo.

"Isso é difícil de se exteriorizar, porque o idoso tenta ainda proteger aquele que lhe agride, na maioria das vezes. Quando eles vêm, eles querem que a gente ouça, mas muitas vezes eles acabam vindo só pra pegar o medicamento. Muitas vezes eles criam barreiras para que a gente não consiga saber que isso acontece. Vêm rapidinho só pra pegar e vão embora. Atrapalha pra gente conseguir visualizar mais as situações" (P3).

Outro empecilho para identificar e abordar a violência é a revelação tardia apontada pelos participantes, porque ao aguentá-la até o limite da tolerância, muitas vezes é difícil manejar ou reverter o problema.

Os profissionais também pontuaram a revelação e recusa de intervenção profissional, descrevendo experiências negativas ao perceber indícios e propor intervenções. Ainda, ouviram relatos na UBS de frustrações de colegas que tentaram aproximação com o usuário ou familiar. Em uma das entrevistas, o profissional comentou que em sua prática, seguidamente os idosos comentavam sobre situações de maus-tratos e pediam silêncio, por temor às consequências. A seguinte fala esclarece a afirmação:

"Só que você também não pode ficar espalhando porque eles te contam e pedem muitas vezes para você não contar. Então eu escuto aquilo como um desabafo. Tanto que muitas das coisas eu não passava para ninguém, estou contando assim no geral, eu nunca contei para ninguém, nem para enfermeira, atéé uma forma que talvez me complique se eles ficarem sabendo, mas para mim é uma ética. Porque se eu contasse aquilo poderia se virar contra mim, porque a minha chefe poderia entender diferente do meu ponto de vista, então acabo não comentando. Então você fica assim, o que é que eu faço agora, vou contar ou não vou. Se você contar pode ser que a família bata nele de novo. Eu estava fazendo certo? Eu não sei se estava fazendo certo, mas foi o jeito que eu achei de fazer" (P7)

Os dados apresentados quanto ao silêncio do idoso, revelação tardia e recusa de interven- ção terapêutica configuram barreiras a transpor quando se trabalha com situações de violência $9,10,24$. Conferem um desafio a mais aos profissionais que, para acompanhar os fatos, precisam além de capacitação, contar com a estrutura e funcionamento do serviço de saúde, que, por sua vez, impõe outras restrições aos profissionais.

Por outro lado, é relevante notar que algumas crenças se solidificam entre os profissionais que justificam a falta de intervenções porque criam ou intensificam temores de trabalhar e desvendar episódios que envolvem violência familiar. Entre as crenças identificaram-se: (a) as famílias que não mudam, ou seja, por mais que o profissional detecte o problema e queira solucioná-lo, não há interesse dos familiares de que os fatos se alterem; (b) quando a situação é confirmada, está tão complicada que é difícil revertê-la; (c) os idosos (ou vítimas de violência em geral) não falam a verdade na investigação; e (d) quando o usuário pede pelo silêncio do profissional, ele deve acatar o pedido com base na ética do sigilo profissional, sem buscar outra alternativa para administrar o problema.

Essas crenças, detectadas no discurso dos profissionais, assinalam atitudes de evitação ou distanciamento de tais situações, posicionamento oposto ao indicado como pressupostos fundamentais para quem trabalha com vítimas de violência 21. Essas atitudes, que representam a falta de resposta do social, diminuem a probabilidade de a vítima também reagir e buscar auxílio em sua rede, o que favorece, em última análise, a invisibilidade dos casos na UBS e na saúde pública 2 .

A segunda categoria, "condições da UBS para atender a situações de violência familiar contra o idoso", apresenta as limitações dos profissionais para atuarem em casos de violência familiar contra o idoso, envolvendo a dinâmica do trabalho na UBS e o preparo da equipe.

A subcategoria "dinâmica de trabalho" abordou as características de funcionamento da UBS que interferem na detecção e manejo de situações de violência familiar contra o idoso, pelos profissionais.

A ausência de interdisciplinaridade ficou evidente nas narrativas dos profissionais que, ou não sabiam com quais colegas podiam contar para solucionar possíveis casos de violência, ou sabiam da sua existência, mas devido a sua rotina não estabeleciam contatos para a troca de informações quando suspeitavam ou evidenciavam uma situação de risco. Outro fator apontado foi o número de profissionais, considerado inferior à demanda de atendimentos na UBS.

A sobrecarga de trabalho foi apontada pelos depoentes como um fator de impedimento para 
a qualidade da relação entre profissional e usuários. Tal situação não os motivava ao rastreamento dos laços familiares, como também não proporcionava ambiente necessário para que o idoso revelasse seus problemas. "É tudo complicado e as pessoas já estão no seu estresse máximo de lidar com as coisas corriqueiras e a violência é mais uma coisa. Só que quanto mais for deixando quieto pior vai ficar" (P4).

"Porque lá [na UBS] é tudo muito corrido. $O$ médico, quando se chega lá pra consultar nem vê direito se você é vermelha, azul ou cor de rosa. muito pouco tempo para o atendimento, então ele não tem tempo pra dar aquela atenção que o idoso precisa. Então nesse tempinho aí ele não vai adquirir confiança em falar com o médico, entendeu?" (P2).

Outro aspecto evidenciado ao longo da pesquisa foi o elevado número de remanejamento de funcionários nos setores, para sanar as faltas do dia ou como alternativa da administração da UBS, para os profissionais terem uma visão abrangente do trabalho ali realizado. Essas alterações se focaram na equipe de enfermagem que constitui o principal contingente de profissionais.

Quanto à administração da violência, todos os fatores apresentados interferem negativamente na possibilidade de escuta, de acolhimento e de sequencialidade nos atendimentos. No entanto, essas atitudes são indispensáveis à construção do vínculo terapêutico que, por sua vez, possibilita ao usuário ter no profissional, uma referência, incluindo-o em sua rede de apoio.

Os participantes relataram também que as rotinas e ações profissionais têm ênfase na saúde física, tornando-se prioritárias em detrimento às questões de ordem social ou emocional.

“...Tanto que antes do aparecimento dessa bendita gripe A nós começamos a fazer um trabalho em sala de espera. Começamos a falar sobre violência do idoso, violência da mulher, cheguei a imprimir uma cartilha de São Paulo sobre violência no idoso, muito boa. Mas daí ficou na casca, porque veio a gripe e acabou com tudo" (P3).

Complementando o que se apresentou nos elementos de análise anteriores, o excesso de trabalho, somado a uma organização que prioriza a saúde do corpo, mantém os profissionais centrados nas tarefas que consideram prioritárias ou emergenciais. Nesse contexto, o trabalho se limita às condutas programáticas e nessa concepção, o rastreamento e a abordagem das violências não são incorporadas às responsabilidades do profissional em relação à saúde do usuário 4,22,25.

A subcategoria "preparo da equipe para atuar em situações de violência” contemplou a percepção dos profissionais sobre as condições da equipe para atender aos usuários idosos no que tange à violência familiar. A falta de capacitação para atuar em tais situações foi mencionada pelos profissionais, que disseram se sentir despreparados.

Já a falta de conhecimento de políticas públicas para administrar a violência familiar contra o idoso se evidenciou durante as entrevistas e se tornou nítida quando os profissionais revelaram não conhecer as orientações governamentais ou municipais a esse respeito.

"Existe o SOS Idoso que coordena todo esse processo de violência contra o idoso. Em nível de prefeitura existe o Conselho Municipal do Idoso, não sei se dentro desse conselho existe alguma coisa" (P9).

A despeito da existência de Políticas Públicas direcionadas à violência contra os idosos, percebeu-se que, na prática, há o desconhecimento da maioria sobre o conteúdo delas. Tal constatação reflete a falta de capacitação dos profissionais da saúde pública sobre o assunto, o que é destacado por estudiosos da área $3,4,12,22$.

Os entrevistados apontaram a ineficácia das ações, pois já haviam tentado interferir em alguns casos atendidos, mas não perceberam a sua resolução. Mencionaram também a dificuldade de articular ações entre os profissionais da UBS para o encaminhamento dos casos suspeitos, por conta da indisponibilidade desses colegas para trabalharem conjuntamente. Ainda alegaram que nem sempre há concordância quanto à caracterização da violência, bem como aos entraves na articulação com outros setores ou órgãos municipais $5,6,7,8,14$.

"Você anda, anda, anda e quando vê continua tudo igual, as pessoas continuam na mesma casa. Eu acho que as pessoas não levam muito a sério, porque têm que mover muitos órgãos. Acho que é porque é trabalhoso resolver o problema das pessoas, daí tem que acionar vários órgãos. Eu acho que é mesmo pelo trabalho, é trabalhoso" (P5).

Uma vez que as ações de saúde ainda se voltam, particularmente, para as enfermidades orgânicas, a falta de medidas de rastreamento para a violência familiar foi apontada como um empecilho.

"Só quando surge algum caso específico [de violência], as pessoas não param pra pensar nisso especificamente, agora quando surge todo mundo acaba se envolvendo, mas ninguém tá procurando nada. Não existe nada relacionado a fazer uma busca ou se vocês perceberem isso ou tais e tais coisas, eu acho que não é tão articulado como na violência contra a mulher em que existe uma estrutura melhor, embora também não funcione 100\%, mas é um pouquinho melhor" (P1). 
Os dados dessa categoria apontam para a necessidade constante de ir à busca das possibilidades, desafiadas constantemente pelos discursos carregados de impotência e impossibilidades. Esses últimos paralisam as ações e geram o perigo da naturalização das situações, a perda da capacidade de crítica e de questionamento 15 .

\section{Considerações finais}

A presente pesquisa buscou identificar as condições de uma UBS para a abordagem profissional de situações de violência familiar contra o idoso, tendo em vista que na última década foram implementadas no Brasil novas políticas públicas direcionadas ao enfrentamento desse agravo.

Os profissionais entrevistados relataram dificuldades no manejo de casos de violência familiar contra o idoso, passando pelo rastreamento, identificação e acompanhamento dos casos. O funcionamento da UBS desfavorecia a detecção e o acompanhamento dos casos em razão da menor ênfase no trabalho interdisciplinar e das rotinas mais voltadas para a saúde física. Apenas os casos extremos se manifestavam, geralmente aqueles que envolviam agressões físicas ou denúncias formalizadas, reforçando as crenças profissionais quanto à dificuldade de manejo dessas situações, favorecendo que outros casos mais sutis permanecessem obscurecidos.

Oferecer cuidado ao outro é uma tarefa complexa que vai muito além do estabelecimento de protocolos e condutas técnicas. Exige o encontro entre seres humanos, que só pode ser viabilizado com disposição e condição do profissional para acolher o usuário na sua humanidade, ou seja, pelo oferecimento de espaço para a escuta do sofrimento humano. A disposição para a escuta precisa permear todos os momentos e contatos do profissional com o usuário, possibilitando o desenvolvimento de sensibilidade para os múltiplos sinalizadores de sofrimento.

Todavia, antes de responsabilizar somente o profissional pela condução dos casos, cabe ressaltar que a violência é um fenômeno interacional e complexo. Para sua compreensão há a necessidade de um olhar ampliado a fim de considerar a interdependência entre os determinantes individuais, relacionais e culturais que a sustentam. Além disso, há que se considerar que a prática profissional é permeada por esses múltiplos fatores, sendo geradora e reprodutora de significados em torno do que é violência e das possibilidades de agir diante de situações em que é percebida.

Considera-se que os dados desta pesquisa apontam para a necessidade de sensibilização dos profissionais da saúde, com o oferecimento de espaço para reflexão e discussão sobre os significados da violência, para que possam reconhecer que se trata de um fenômeno impreciso, mutante e subjetivo. Precisa-se investir nesse reconhecimento para que os profissionais sejam capazes de dialogar com os usuários e mostrar que há possibilidades de enfrentamento, mas que trabalhar com situações de violência envolve incerteza. É necessário que tentem encontrar, com o auxílio dos envolvidos, alguma resposta que, embora não definitiva, permita o diálogo sobre a questão e possibilite retirá-los do isolamento.

Dialogar sobre situações de violência não beneficia apenas o idoso e o agressor, como também o profissional que sabe da existência dessas situações e se sente incapacitado de atuar, pois essa insatisfação repercute na sua saúde e bem-estar. Perceber os sinais de violência e não oferecer ajuda se configura como uma revitimização do idoso, proporcionada pelas condições de atendimento no sistema de saúde.

A pessoa que cuida de outra pessoa profissionalmente e que está cotidianamente envolvida com dilemas humanos requer também um espaço para ser escutada. Sendo assim, sugere-se a oferta de supervisão profissional e institucional por parte dos gestores públicos, proporcionando a escuta da equipe e incentivando maior participação do profissional nas tomadas de decisão e articulação dos serviços prestados.

Entende-se que essas medidas seriam contribuições para a proposta de integralidade nas ações de saúde preconizada pelas políticas públicas. Vale lembrar que cabe ao setor saúde ir além de medidas curativas, buscando participar das questões sociais e definir medidas que contribuam para a promoção da saúde, compreendida como bem-estar individual e coletivo.

Por mais que os dados desta pesquisa abram para a possibilidade de se pensar a abordagem da violência familiar contra o idoso no contexto da atenção básica, os resultados ainda são restritos à realidade de uma UBS. Portanto, é necessário que outros pesquisadores sigam investigando as barreiras encontradas para uma ação profissional mais efetiva nesses casos. Avalia-se como urgente a necessidade de convergir esforços para políticas públicas direcionadas a cuidar dos profissionais que trabalham com dilemas humanos críticos, entre eles as situações de violência. 


\section{Resumen}

Este artículo tiene como objetivo describir el enfoque profesional de la violencia familiar contra las personas mayores en una unidad básica de salud (UBS). Es un estudio cualitativo, con datos recogidos a través de la observación de participantes con notas en un diario de campo y entrevistas semiestructuradas. Participaron diez profesionales y los datos fueron analizados según la Grounded Theory y se discutieron dos categorías: la gestión profesional de las situaciones de violencia doméstica contra las personas mayores y las condiciones de la UBS para atender situaciones de violencia familiar contra los ancianos. Los datos apuntan a dificultades profesionales para identificar la violencia y creencias relacionadas con la incapacidad para hacerla frente. En términos institucionales, indican factores que dificultan la detección y el seguimiento de los casos como un menor énfasis en el trabajo interdisciplinario y rutinas centradas en la salud física. Se sugiere la necesidad de ofrecer a los profesionales una oportunidad para la reflexión sobre la violencia y las posibilidades de intervención.

Anciano; Violencia Doméstica; Personal de Salud; Atención Primaria de Salud.

\section{Colaboradores}

A. C. N. S. Wanderbroocke participou da concepção da pesquisa, coleta de dados, análise de dados e redação do artigo. C. L. O. O. Moré participou da concepção da pesquisa, análise dos dados, revisões crítica e final do artigo.

\section{Referências}

1. Minayo MCS. Violência e saúde. Rio de Janeiro: Editora Fiocruz; 2006.

2. Fuster EG. Las víctimas invisibles de la violencia familiar. El extraño iceberg de la violencia doméstica. Buenos Aires: Paidós; 2002.

3. Abbey L. Elder abuse and neglect: when home is not safe. Clin Geriatr Med 2009; 25:47-60.

4. Halphen JM, Varas GM, Sadowsky JM. Recognizing and reporting elder abuse and neglect. Geriatrics 2009; 64:13-8
5. Braz M, Cardoso MHCA. Em contato com a violên cia - os profissionais de saúde e seus pacientes vítimas de maus-tratos. Rev Latinoam Enferm 2000; 8:91-7.

6. Lettiere A, Nakano MAS, Rodrigues DT. Violência contra a mulher: a visibilidade do problema para um grupo de profissionais da saúde. Rev Esc Enferm USP 2008; 42:467-73. 
7. Andrade CJM, Fonseca RMGS. Considerações sobre a violência doméstica, gênero e o trabalho das equipes de saúde da família. Rev Esc Enferm USP 2008; 42:591-5.

8. Lacman S, Ghirardi MIG, Castro ED, Tuarek TA. A. Repercussões da violência na saúde mental de trabalhadores do Programa Saúde da Família. Rev Saúde Pública 2009; 43:682-8.

9. González MGR, Zinder NS. Factores asociados con el auto-reporte de maltrato en adultos mayores de México. Rev Chil Salud Pública 2009; 13:90-9.

10. Killick C, Taylor BJ. Professional decision making on elder abuse: systematic narrative review. J Elder Abuse Negl 2009; 21:211-38.

11. Florêncio MVL, Ferreira Filha MO, Sá LD. A violência contra o idoso: dimensão ética e política de uma problemática em ascensão. Rev Eletrônica Enferm 2007; 9(3). http://www.fen.ufg.br/revista/ v9/n3/v9n3a23.htm.

12. Souza ER, Ribeiro A, Peixoto AS, Souza AC, Marques C. Rede de proteção aos idosos do Rio de Janeiro: um direito a ser conquistado. Ciênc Saúde Coletiva 2008; 13:1153-63.

13. Yaffe MJ, Wolfson C, Lithwick M. Professions show different enquiry strategies for elder abuse detection: Implications for training and interprofessional care. J Interprof Care 2009; 23:646-54.

14. Lobato GR, Moraes CL, Nascimento MC. Desafios da atenção à violência doméstica contra crianças e adolescentes no Programa Saúde da Família em cidade de médio porte do Estado do Rio de Janeiro, Brasil. Cad Saúde Pública 2012; 28:1749-58.

15. Moré CLOO, Macedo RMS. A psicologia na comunidade: uma proposta de intervenção. São Paulo: Casa do Psicólogo; 2006.

16. Penso MA, Almeida TMC, Brasil KCT, Barros CA, Brandão CL. O atendimento a vítimas de violência e seus impactos na vida de profissionais da saúde. Temas Psicol 2010; 18:137-52.
17. Brasil. Lei no 10.741, de 1o de outubro de 2003 . Dispõe sobre o Estatuto do Idoso. Diário Oficial da União 2003; 3 out.

18. Secretaria Especial dos Direitos Humanos. Plano de ação para o enfrentamento da violência contra a pessoa idosa. Brasília: Secretaria Especial dos Direitos Humanos; 2007.

19. Strauss A, Corbin J. Pesquisa qualitativa. Técnicas e procedimentos para o desenvolvimento de teoria fundamentada. Porto Alegre: Artmed; 2008.

20. Núcleo Técnico da Política Nacional de Humanização, Secretaria de Atenção à Saúde, Ministério da Saúde. Acolhimento nas práticas de produção de saúde. 2a Ed. Brasília: Ministério da Saúde; 2006.

21. Moré CLOO, Cantera L. La violencia contra la mujer y la práctica profesional: la perspectiva de la familia, redes de apoyo e interdisciplinariedad. In: I Congreso de Intervención para el Estudio de la Violencia Contra las Mujeres. La intervención multidisciplinar. Sevilla: Consejeria para la Igualdad y Bienestar Social; 2010. p. 1-12.

22. Hanada H, D’Oliveira AFPL, Schraiber LB. Os psicólogos na rede de assistência a mulheres em situação de violência. Revista Estudos Feministas 2010; 18:33-60.

23. Costa L, Penso MA, Almeida TMC. O grupo multifamiliar como um método de intervenção em situações de abuso sexual infantil. Psicol USP 2005; 16:121-46.

24. Silva AG, Moraes CL, Reichenheim ME. Violência física entre parceiros íntimos: um obstáculo ao início do acompanhamento da criança em unidades básicas de saúde do Rio de Janeiro, Brasil? Cad Saúde Pública 2012; 28:1359-70.

25. Bonfim EG, Lopes MJM, Peretto M. Os registros profissionais do atendimento pré-natal e a (in)visibilidade da violência doméstica contra a mulher. Esc Anna Nery Rev Enferm 2010; 14:97-104.

Recebido em 05/Dez/2012

Versão final reapresentada em 13/Mai/2013 Aprovado em 12/Jul/2013 